\title{
A Case of Fulminant Amebic Colitis Diagnosed after Colonic Resection
}

Tatsuya Ishii ${ }^{\star \star}$, Nobuhiro Takeuchi ${ }^{1}$, Masanori Takada ${ }^{1}$, Akihito Otsuka $^{2}$ and Yusuke Nomura ${ }^{2}$

${ }^{1}$ Division of Emergency Medicine, Department of Internal Medicine, Kawasaki Hospital, Japan

${ }^{2}$ Department of Internal Medicine, Kawasaki Hospital,3-3-1 Higashiyama-cho, Hyogo-ku, Kobe-shi, Hyogo 652-0042, Japan

*Corresponding author: Tatsuya Ishii, Division of Emergency Medicine, Department of Internal Medicine, Kawasaki Hospital, Japan, Tel: +81-78-511-3131; Fax: +81-78-511-3138; E-mail: ishii_tatuya@kawasaki-hospital-kobe.or.jp

Rec date: Feb 09, 2016; Acc date: Mar 05, 2016; Pub date: Mar 08, 2016

Copyright: ( 2016 Ishii T, et al. This is an open-access article distributed under the terms of the Creative Commons Attribution License, which permits unrestricted use, distribution, and reproduction in any medium, provided the original author and source are credited

\begin{abstract}
Here, we report a case of fulminant amebic colitis diagnosed after colonic resection in a 66-year-old male who visited our hospital complaining of prolonged fever and consistent pain in the right abdomen. The patient had neither watery nor bloody stool. Laboratory data revealed increased white blood cell counts $(15,900 \mathrm{cells} / \mu \mathrm{l})$ and high levels of C-reactive protein $(10.3 \mathrm{mg} / \mathrm{dl})$. Contrast enhanced computed tomography revealed remarkably hypertrophic and edematous lesions in the right-sided colon. Stool culture revealed no pathogens. The patient was suspected to have infectious colitis; thereafter, the antibiotic flomoxef sodium ( $3 \mathrm{~g} /$ day) was administered. Colonoscopy revealed a circumferential white coat and stripped mucosal lesions in the right-sided colon; thereafter, ischemic colitis or enterohemorrhagic Escherichia coli colitis was the differential diagnosis. When the general condition of the patient and their inflammatory response deteriorated, surgical treatment was adopted. Surgical findings revealed a rightsided necrotizing colon and yellowish ascites, which was later found to contain Enterococcus faecalis and grampositive bacillus. Pathological findings revealed the presence of trophozoites of Entamoeba histolytica. Consequently, fulminant amebic colitis was diagnosed. The postoperative course was uneventful, and the patient was discharged on postoperative day 18.
\end{abstract}

Keywords: Fulminant Amebic Colitis; computed tomography; Entamoeba histolytica

\section{Introduction}

Amebic colitis is caused by oral infection of trophozoites of Entamoeba histolytica. Many cases of amebic colitis present with mild symptoms. However, rare cases presenting with severe symptoms, including megacolon, colonic perforation, and sepsis, can occur in fulminant amebic colitis (FAC). Diagnostic imaging of FAC is challenging; computed tomography (CT) reveals markedly hypertrophic colon walls, which mimic tumoral lesions. In some FAC cases, surgical resection of infected colon is crucial for the proper diagnosis and treatment. Here, we report a case of FAC in which preoperative findings made the diagnosis.

\section{Case Report}

A 66-year-old male was admitted to our hospital with complaints of low-grade fever and persistent right, lower abdominal pain. His medical history included diabetes mellitus and hypertension. He visited Singapore 5 years ago on vacation. He denied any homosexual behavior and alcohol or tobacco use. He began feeling right-sided, lower abdominal discomfort at the end of July 2015. He first visited a private clinic in Japan where he was diagnosed with colitis and given an oral antibiotic (levofloxacin, $500 \mathrm{mg}$ /day). Despite this treatment, his condition did not improve. He then visited our hospital for further examination. His blood pressure was $119 / 77 \mathrm{mmHg}$, heart rate was 105 beats $/ \mathrm{min}$, and body temperature was $37.5^{\circ} \mathrm{C}$. Blood chemistry analyses revealed inflammation $(15,900$ white blood cells/ $\mu$ with 83.3\% neutrophils; $10.3 \mathrm{mg} / \mathrm{dl}$ C-reactive protein), coagulant dysfunction (49.9 s activated partial thromboplastic time; $21.3 \mu \mathrm{g} / \mathrm{ml}$ fibrinogen degradation products), moderately impaired glucose tolerance $(226 \mathrm{mg} / \mathrm{dl}$ glucose; $8.9 \%$ hemoglobin A1c). Further, mildly decreased total protein $(6.3 \mathrm{~g} / \mathrm{dl})$ and albumin $(3.13 \mathrm{~g} / \mathrm{dl})$, mildly elevated lactate dehydrogenase (358 IU/l) were revealed (Table 1).

\begin{tabular}{|c|c|c|c|c|c|}
\hline WBC & $15900 / \mu \mathrm{l}$ & $\mathrm{TP}$ & $6.3 \mathrm{~g} / \mathrm{dl}$ & PT & $91 \%$ \\
\hline Neutro & $83.30 \%$ & Alb & $3.13 \mathrm{~g} / \mathrm{dl}$ & APTT & $49.9 \mathrm{sec}$ \\
\hline $\mathrm{RBC}$ & $419 \times 10^{4} / \mu \mathrm{l}$ & T-Bil & $0.3 \mathrm{mg} / \mathrm{dl}$ & FDP & $21.3 \mu \mathrm{g} / \mathrm{ml}$ \\
\hline $\mathrm{Hb}$ & $12.9 \mathrm{~g} / \mathrm{dl}$ & YGTP & $14 \mathrm{IU} / \mathrm{I}$ & & \\
\hline $\mathrm{Ht}$ & $39.30 \%$ & ALP & $314 \mathrm{IU} / \mathrm{I}$ & Glu & $226 \mathrm{mg} / \mathrm{ml}$ \\
\hline \multirow[t]{4}{*}{$\mathrm{MCV}$} & $93.8 \mathrm{fl}$ & AST & $20 \mathrm{IU} / \mathrm{I}$ & $\mathrm{HbA1c}$ & $7.80 \%$ \\
\hline & & ALT & $37 \mathrm{IU} / \mathrm{I}$ & & \\
\hline & & $\mathrm{LDH}$ & $358 \mathrm{IU} / \mathrm{I}$ & & \\
\hline & & CK & $54 \mathrm{IU} / \mathrm{I}$ & HBs-Ag & $(-)$ \\
\hline \multirow[t]{2}{*}{ CRP } & $10.3 \mathrm{mg} / \mathrm{dl}$ & BUN & $13.5 \mathrm{mg} / \mathrm{dl}$ & $\mathrm{HBc}-\mathrm{Ab}$ & $(-)$ \\
\hline & & $\mathrm{Cr}$ & $0.85 \mathrm{mg} / \mathrm{dl}$ & $\mathrm{HCV}-\mathrm{Ab}$ & $(-)$ \\
\hline CEA & $1.3 \mathrm{ng} / \mathrm{ml}$ & $\mathrm{Na}$ & $138 \mathrm{mEq} /$ & RPR & $(-)$ \\
\hline \multirow[t]{2}{*}{ CA19-9 } & $16.7 \mathrm{U} / \mathrm{ml}$ & $\mathrm{K}$ & $4.9 \mathrm{mEq} / \mathrm{l}$ & TPHA & $(-)$ \\
\hline & & $\mathrm{Cl}$ & $100 \mathrm{mEq} / \mathrm{l}$ & HIV-Ab & $(-)$ \\
\hline
\end{tabular}

Table 1: Laboratory data at admission.

Abdominal X-ray revealed no abnormal findings (Figure 1a). Contrast enhanced CTrevealed a swollen and edematous colon from 
Citation: Ishii T, Takeuchi N, Takada M, Otsuka A, Nomura Y (2016) A Case of Fulminant Amebic Colitis Diagnosed after Colonic Resection. J Clin Case Rep 6: 736. doi:10.4172/2165-7920.1000736

Page 2 of 3

the cecum to the middle of the ascending colon without an evidence of abscess in the liver or ascites in the abdominal cavities (Figure 1b). At this point, bacterial colitis was suspected. A fecal culture was submitted and the antibiotic flomoxef sodium ( $3 \mathrm{~g} /$ day) was administered.

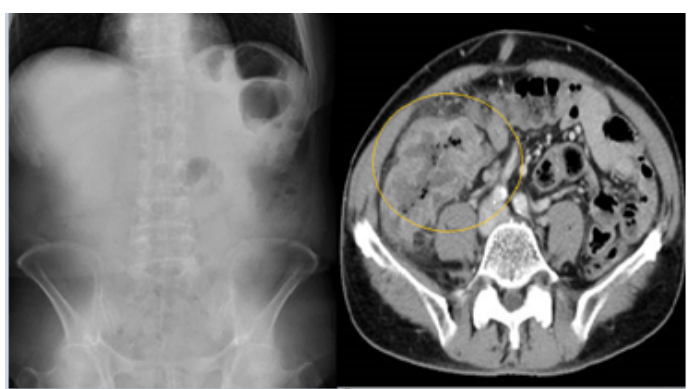

a

b

Figure 1: (a) Abdominal X-ray revealed no abnormal findings. (b) Contrast enhanced computed tomography revealed hypertrophic and edematous lesions in the right-sided colon.

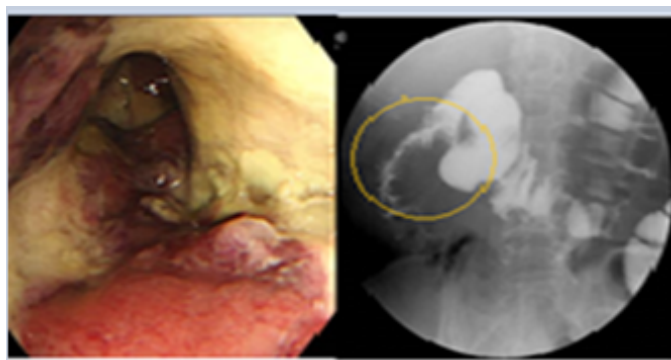

a

b

Figure 2: (a) Colonoscopy revealed a circumferential white coat and necrotizing mucosa. (b) Gastrografin enema during colonoscopy revealed extensive stenotic lesions in the right-sided colon. (c) Microscopic specimens revealed marked infiltration of inflammatory cells.

On day 8 , colonoscopy was performed, and the findings suggested gangrenous colitis with necrotizing mucosa and a circumferential white coat (Figure 2a). Gastrografin enema under colonoscopy revealed extensive stenotic lesions in the ascending colon (Figure 2b). These findings were consistent with ischemic colitis or enterohemorrhagic Escherichia coli colitis. Stool culture revealed no presence of pathogens. Surgical treatment was indicated when abdominal symptoms and inflammatory response levels worsened. On day 11, right-sided colon resection was performed (Figure 3a), and yellow, dense ascites was found. Ascites culture revealed the presence of Enterococcus faecalis and gram-positive bacillus. Microscopic specimens (Figure $3 \mathrm{~b}$ ) revealed the presence of trophozoites of $E$. histolytica and extensive necrotizing colon. At this point, the patient was diagnosed with FAC. On postoperative day 4, E. histolytica antibody staining was positive, and administration of the antibiotic metronidazole ( $1500 \mathrm{mg} /$ day) was initiated. On postoperative day 4 , inflammatory response levels improved (6700 white blood cells $/ \mu$ l; 0.2 $\mathrm{mg} / \mathrm{dl}$ C-reactive protein), and the patient was discharged on postoperative day 18. The clinical course is shown in Figure 4.

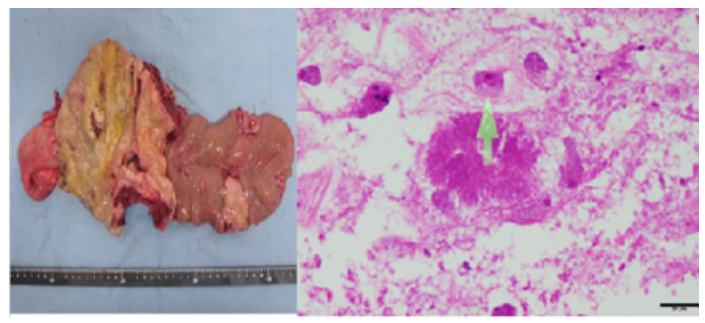

a

b

Figure 3: (a) Gross specimen; resected lesion. (b) Microscopic specimens exhibiting trophozoites of Entamoeba histolytica with extensive necrotizing colon.

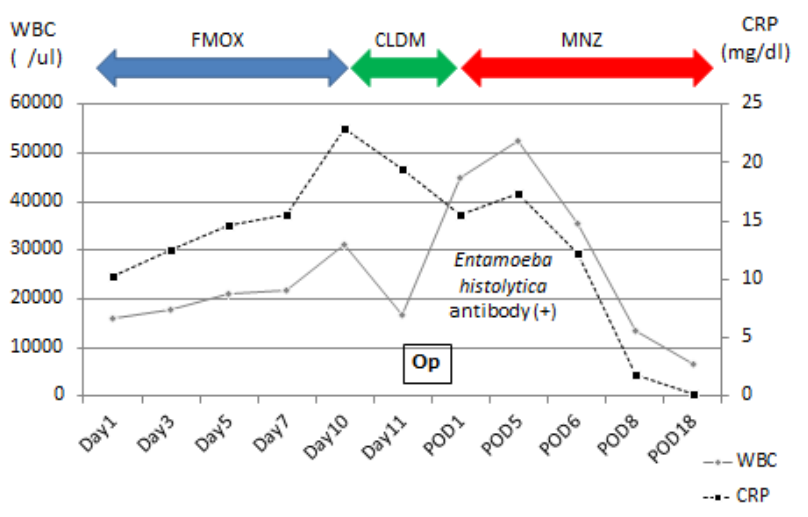

FMOX: Flomoxef CLDM: Clindamycin MNZ: Metronidazole Op: Operation

Figure 4: Clinical course.

\section{Discussion}

Entamebiasis dramatically prevailed soon after World War II in Japan, then declined for some time. However, with the recent travel boom, increase in male homosexual behavior, and incidence of mass infections in facilities for the disabled, the prevalence of $E$. histolytica is on the rise. E. histolytica infection begins with oral transmission of amebic cysts that are passed to the small intestines where they are excystated and become trophozoites. Typically, entamebiasis leads to a chronic course, presenting with mucus and blood in the stool. Almost all who contract E. histolytica remain carriers, and approximately $10 \%$ present with symptoms of amebic colitis, including bloody and watery diarrhea, and abdominal pain $[1,2]$. It is reported that about $3 \%$ of amebic colitis cases are fulminant type, leading to intestinal perforation or peritonitis [1,2]. FAC is a fatal condition in which colon perforation or multiple organ failure is followed by rapid and extensive necrosis of all colonic layers. Characteristic symptoms of FAC include fever, abdominal pain, or consciousness disturbance caused by colonic necrosis and peritonitis, and abdominal distension caused by toxic megacolon. Progression of FAC is considered to stem from the toxic release of enzymes from amebic mites, secretion of inflammatory 
Citation: Ishii T, Takeuchi N, Takada M, Otsuka A, Nomura Y (2016) A Case of Fulminant Amebic Colitis Diagnosed after Colonic Resection. J Clin Case Rep 6: 736. doi:10.4172/2165-7920.1000736

Page 3 of 3

cytokines, or thrombotic occlusion caused by amebic invasion of the arteries supplying blood to the colon.

Amebic colitis diagnosis includes: i) detection of $E$. histolytica by stool sample or biopsy, ii) detection of specific bacterial DNA, iii) the diagnosis of antibodies in the serum, and/or iv) colonoscopy, CT, or barium enema findings. One CT finding for amebic colitis is a hypertrophic colon and intramural gas, which suggests a fulminant condition; however, this finding is not necessarily specific to FAC. Preoperative diagnosis of FAC is particularly low, ranging from $0 \%$ $50 \%$ [3,4]. Preoperative diagnosis of FAC is generally considered challenging, and sometimes a differential diagnosis of inflammatory or infective colitis is necessary. Because FAC is associated with high mortality [2], immediate administration of metronidazole should be considered soon after the condition is suspected or diagnosed. If FAC is suspected from clinical symptoms, and/or social history or travel history, further examination to confirm the condition is crucial. In many cases, postoperative pathological findings confirm FAC. If a preoperative diagnosis of FAC is possible, immediate resection of the infected colon should performed. Surgical management of FAC is not standardized. Eggleston et al. [5] reported that surgical resection of the infected colon result in a higher mortality rate $(71 \%)$ compared to the creation of intestinal fistula to divert the fecal stream (43\%). On the other hand, a higher survival rate has been reported with more extensive colonic resection [6]. Another report concluded that there was no difference in survival rates between extensive and limited colonic resection [7]. Regardless, less invasive surgery is desirable to optimize the operation time and surgical intervention.

FAC risk is considered to increase with age, use of steroidal or immunosuppressant drugs, and certain underlying conditions, including HIV-infection, poorly controlled diabetes mellitus, and malignant tumors; however, the mechanisms remain unclear. In our case, the patient's only potential risk factor was poorly controlled diabetes mellitus. Although differential diagnosis of FAC is challenging from clinical presentations and medical examinations, further consideration of preoperative diagnoses related to this condition should is necessary to decide medical management.

\section{Conclusion}

We reported a case of FAC diagnosed after colonic resection. In some FAC cases, surgical resection of infected colon is crucial for the proper diagnosis and treatment. When a patient presents with symptoms of severe colitis and conservative treatment is ineffective, a differential diagnosis of FAC should be considered.

\section{References}

1. Adams EB, MacLeod IN (1977) Invasive amebiasis. I. Amebic dysentery and its complications. Medicine (Baltimore) 56: 315-323.

2. Aristizábal H, Acevedo J, Botero M (1991) Fulminant amebic colitis. World J Surg 15: 216-221.

3. Ellyson JH, Bezmalinovic Z, Parks SN, Lewis FR Jr (1986) Necrotizing amebic colitis: a frequently fatal complication. Am J Surg 152: 21-26.

4. Ozdogan M, Baykal A, Aran O (2004) Amebic perforation of the colon: rare and frequently fatal complication. World J Surg 28: 926-929.

5. Eggleston FC, Verghese M, Handa AK (1978) Amoebic perforation of the bowel: experiences with 26 cases. Br J Surg 65: 748-751.

6. Ohe T, Yamaguchi T, Kitakado Y (2004) A Case of Successfully Treated Amebic Colitis with Total Colon Necrosis. J Jpn Assoc 65: 3231-3235.

7. Muto Y, Watanabe Y, Maruyama T (2008) A Case of Fulminant Amebic Colitis. J Jpn Assoc 69: 1134-1139. 